\title{
A seat at the table for rural drinking water
}

\author{
An interview with Adriana Renteria, Regional Water Management Coordinator, \\ Community Water Center
}

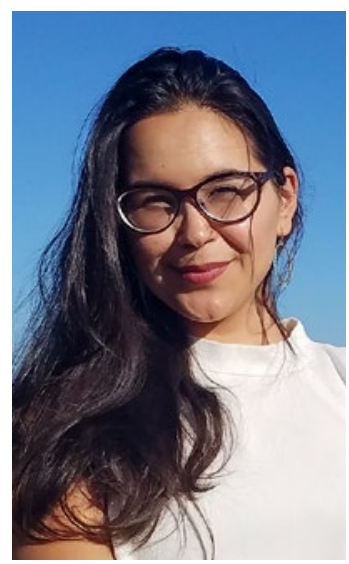

Adriana Renteria

A sprinkler line in the southern San Joaquin Valley.

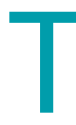

he Community Water Center (www.communitywatercenter.org) is a nonprofit organization that works through education, organizing and advocacy to increase access to clean water. Founded in 2006, it has offices in Visalia and Sacramento and focuses on domestic water issues in California's rural agricultural areas. Adriana Renteria is the Community Water Center's regional water management coordinator. She leads the group's involvement in the implementation of the Sustainable Groundwater Management Act (SGMA), working in particular to increase public participation in groundwater planning and management.

\section{Tell us about CWC's involvement in the GSA/GSP processes at the local level.}

We have been involved since the early stages of the development of the legislation, and helped to advocate for the inclusion of drinking water seats on several groundwater sustainability agency (GSA) boards and committees. We try to make the groundwater planning and management processes accessible to more people and to increase public participation.

We have held a series of groundwater workshops, and we helped the Union of Concerned Scientists develop a guide to participation in the SGMA process (https://goo.gl/Agxy3U). There are statutory requirements in SGMA that require stakeholder engagement. Through our workshops we've shared information about how to get involved in the GSA processes and the development of groundwater sustainability plans (GSPs) - so that all stakeholders know what SGMA means for their community, what a water budget is, what sorts of questions to ask the consultants that are preparing the GSPs, and what questions to ask in GSA board and committee meetings. Generally, it's about sharing tools and resources that demystify the technical components of groundwater planning in order to lessen this barrier of participation.

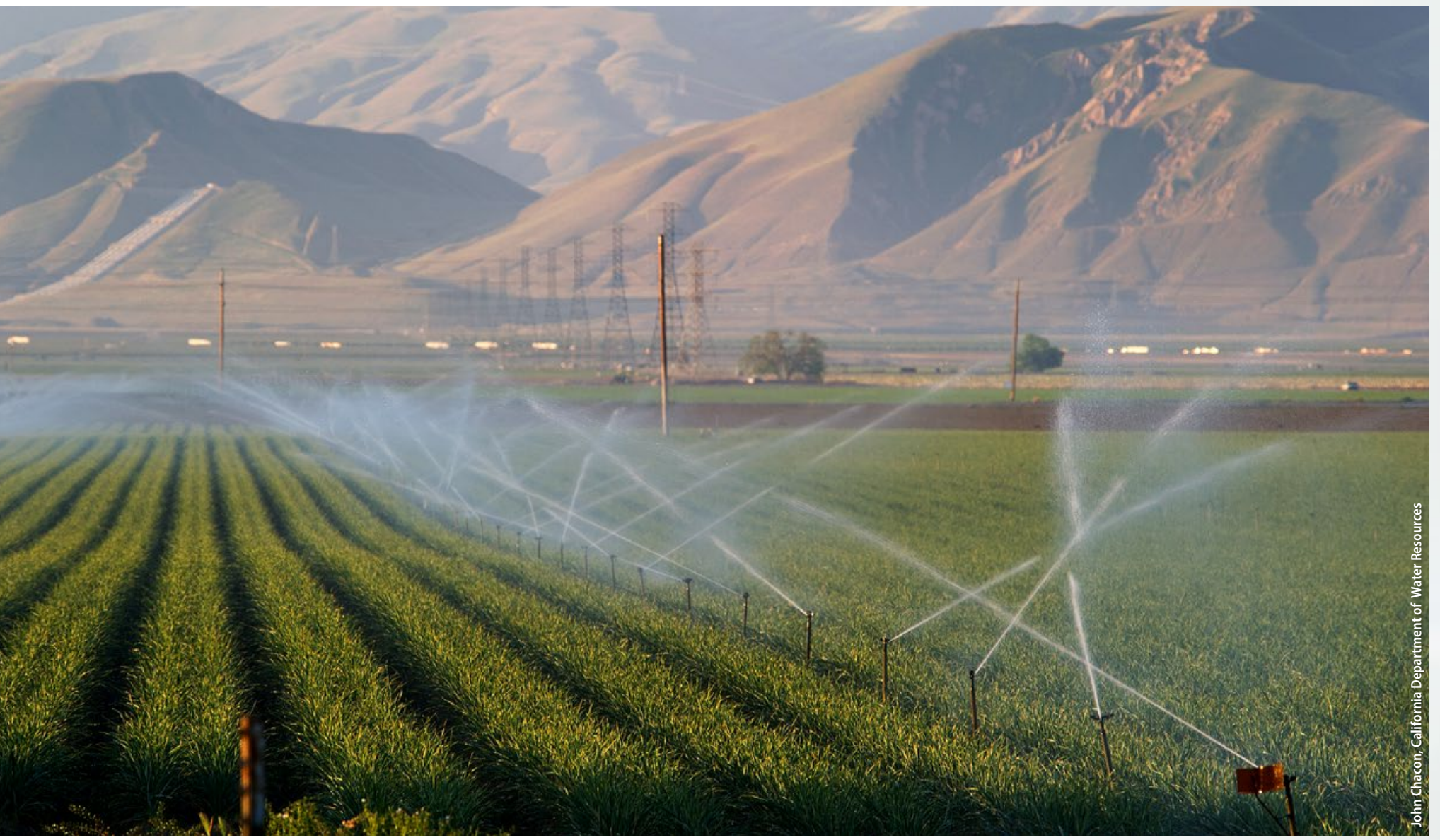




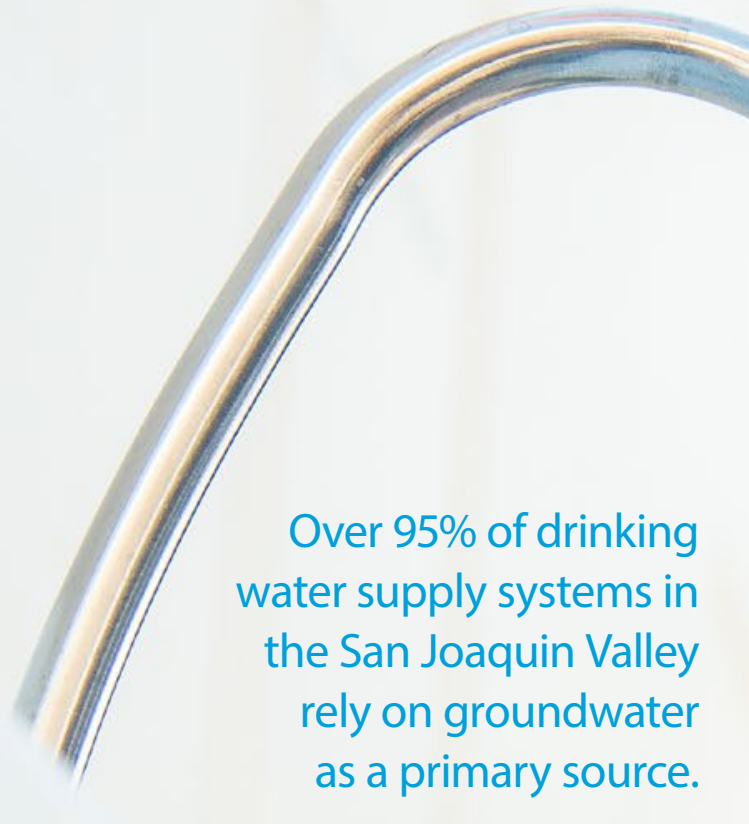

We also, as an organization, are members of various GSA technical advisory committees and stakeholder advisory committees. These stakeholder advisory committees are one way that many GSAs are trying to incorporate stakeholder interests, and drinking water interests in particular. Some GSAs also have drinking water interests represented on their governing board. Where we are on stakeholder advisory committees we work with the drinking water districts in the area to ensure they are knowledgeable on important GSA information and can share their feedback and concerns. The GSAs we are most involved in are located in Tulare, Fresno and Kings counties. CWC has prioritized these GSAs because many communities in these areas rely on groundwater as a primary drinking water source. Many small, rural communities are vulnerable to groundwater depletion and oftentimes do not have the financial means to drill new wells or seek new sources of water if they find themselves facing water quantity or quality concerns. For these reasons, it's important for representatives from drinking water districts to participate in the management of their local groundwater resources.

\section{What are your main concerns with respect to the representation of all groundwater users the groundwater management?}

The main thing is that, in developing GSPs, GSAs have to come together to set the criteria for each of the six "undesirable impacts" of SGMA (see page 4). For example, what is the minimum threshold for groundwater depletion that each GSA will allow. For different stakeholders, the acceptable level of depletion may be very different. Agriculture, large municipal water districts, and industry stakeholders generally have the capacity to drill deeper wells, and are not as vulnerable 
to groundwater depletion as small community service districts that have shallower wells and limited financial capacity to address water shortage and water quality concerns.

Groundwater quality is another issue. GSAs have to set minimum thresholds for how much degradation of groundwater quality they are going to allow (though aquifers used for drinking water still have to abide by state and federal drinking water standards and irrigators have to comply with state regulatory programs). Input from stakeholders dealing with water quality concerns is important to get a better understanding of the overall water quality state of the basin. As GSAs develop proposed projects to reach sustainability, it's important for them to identify multi-benefit water projects that can address both water supply and quality concerns.

\section{How well are state efforts to support inclusive groundwater management working? What needs improvement?}

Over $95 \%$ of the drinking water supply systems in the San Joaquin Valley rely on groundwater as a primary source. Yet the majority of representation is the agricultural industry. So, we are concerned.

The Department of Water Resources (DWR) has released documents on best management practices (available at https://goo.gl/e1CPmV and https://goo. gl/1nido6) for the stakeholder engagement that is required under SGMA. DWR is also offering facilitation support services, where a third-party professional would come in to facilitate discussions and meetings and help coordinate outreach to different stakeholders. And there is a DWR SGMA point person in every region, and then also a DWR point of contact at an even more local level.

But DWR has also stated several times that its role is not to enforce how GSAs should develop their GSPs. SGMA is very rooted in the concept that local decisionmakers should be the ones making the decisions about managing their resources.

While some GSAs in Kern and Kings counties used the DWR's facilitation service during the GSA formation process, currently no GSAs in the southern San Joaquin Valley are using the services as part of the GSP development process. Not every subbasin is interested in third-party facilitation.

We think facilitation support for stakeholder engagement is something that subbasins would greatly benefit from and should be taking advantage of. We feel that it would be helpful for DWR to do more targeted outreach during the GSP development process - and the DWR's coordinator of facilitation and support services has definitely been very understanding and responsive to suggestions when we have met.

Also, because it's early, there is still a lot of uncertainty around many topics. One of the big uncertainties has been how the SGMA requirements interact with and complement the existing regulatory and planning programs - like the Irrigated Lands Regulatory Program and CV-SALTS program (which concerns water quality). DWR is still working on providing GSAs additional guidance on that. Another issue is how the GSAs are going to address how depletion of interconnected surface waters impacts groundwater-dependent ecosystems.

\section{Closing thoughts?}

I'd just point to some challenges, some reasons why public participation might not be as inclusive as it could be.

One thing is that the timeline for GSP development is definitely quick. Because of that, the GSAs should reflect on how they are doing outreach to share updates, to make sure that all beneficial users of water, including domestic well users, are aware of meetings and plan updates. GSAs should be, or should start, working with schools, community-based organizations, nonprofits, and local bilingual media stations to make sure the general public is knowledgeable about SGMA and aware of opportunities to engage in local groundwater planning. This is statutorily required - inviting a diverse group of people to participate means that you have to communicate in a diverse way.

Another barrier is that GSA meetings tend to take place during the day, when irrigation district and other city and county staff are at work - so they can attend the meetings on the clock. But many other people are not able to attend meetings during regular working hours.

In addition, the technical and stakeholder advisory committees must present technical information in an accessible way that allows for questions from the public, for working through uncertainty, for really having an understanding of what's happening in the basin. You can't just present something and then approve it the next week without giving stakeholders enough time to understand the impacts the policy will have on their community. It is up to the GSA chairs and subbasin facilitators to work with consultants to make sure information presented is understood and that their GSP development timeline is transparent and clearly defined.

I just think that, across the board, inclusion could be improved. GSAs really should be taking the lead from those GSAs who are taking their stakeholder communication and engagement plans seriously and are using this step of the GSP development process as an opportunity to engage their communities in groundwater management.

The Community Water Center offers resources about SGMA for stakeholders at www.communitywatercenter. org/sgma_engagement. CA 